\title{
Digitalization of education and its impact on the teaching of foreign languages to students of technical universities
}

\author{
Irina Shcherbakova ${ }^{1}$, Nadezhda Kovalchuk ${ }^{1}$, Maria Timashova ${ }^{1}$, Boris Konkin ${ }^{2}$, Julia \\ Soprantsova ${ }^{1, *}$ \\ ${ }^{1}$ Don State Technical University, Gagarin sq., 1, Rostov-on-Don, 344003, Russia \\ ${ }^{2}$ North Caucasus branch of Moscow Technical University of Communications and Informatics, \\ Serafimovitcha str., 62, Rostov-on-Don, 344002, Russia
}

\begin{abstract}
The scientific article is devoted to the study of the peculiarities of digitalization of education in the framework of teaching foreign languages to students of technical universities. On the basis of the theoretical study of the informative features of the digitalization processes in the field of education, the authors point out the basic components in the system of digital foreign language teaching for students of technical universities. The article also discusses a number of disadvantages and advantages of the social, psychological, organizational and pedagogical nature of this system, reflecting the relevance of the problem of digitalization of training procedures, as well as the absolute transition to distance learning in the current requirements of the development of higher education.
\end{abstract}

\section{Introduction}

In terms of the current stage of development, under the influence of the increasing spread of information technologies in all areas of public life, the role of the task of training highly qualified specialists in the active digitalization of absolutely all economic management procedures, in particular of the structure of higher education, is increasing. Despite this, there are contradictions of social and cultural nature, which have a negative impact on the effectiveness of the competent and professional training of students of technical universities. They are often expressed in differences of technical equipment status and information structures, the preservation of the volume of information flow, according to specific subject areas and the degree of professionalism in the field of digitalization of teachers, the current essencial requirements to a number of professional qualification, the essence of study programs standards and the requirements of the implementation of continuous education on the basis of the formation of a unified electronic information educational space.

\footnotetext{
*Corresponding author: soprik83@mail.ru
} 


\section{Methods, techniques and technologies used}

In our work, we used various methods, including theoretical; empirical (observation, questioning). The perspective direction is reflected in the following modern projects in the field of education: "Modern digital educational environment in Russia" (2016-2021), "Digital School" (2018-2025), "Strategy for the development of the Information Society in Russia for 2017-2030" (Decree of the President of the Russian Federation No. 203 of 09.05.2017). Based on this, one of the tasks of the presented scientific article is to study the characteristics of the problem of digitalization of the educational professorship in the aspect of teaching foreign languages to students of technical universities.

\section{Results}

In order to follow the task in the framework of the presented scientific article, we will analyze the essential features of the concept of «digitalization».

1.1 The superficial meaning of this term implies the formation of the latest digital types that produce information flows between public entities

According to V. G. Khalin's judgment: «... if the digital modification of information meets a certain number of necessary requirements, then it includes: production, science, business, social sphere and everyday life of the people; it is accompanied only by the effective application of its results; ... its results are used not only by professionals and specialists, but also by ordinary citizens; users of digital information have experience of interaction with it» [1].

1.2 It should also be noted that when understanding the term «digitalization of education», it should not be compared with the process of informatization

The process of informatization in the educational sphere is aimed at the progress of the telecommunications structure with the aim of effective network relationships between various educational entities and the joint use of information and methodological capabilities in the training of specialists of various profiles. In turn, the term «digitalization» in the encyclopedic and dictionary literature is formulated as «the transition to a digital method of recording, communication, and transmission of information using digital devices» [2].

1.3 The context of understanding this process leads to the transformation of the paradigm of relations between social actors, in particular for general education purposes

It is not only a transition to electronic interaction of educational subjects. It is focused on «synthetic solutions of managerial, infrastructural, cultural and behavioral characters» [3]. For example, the digitization of various kinds of student information simplifies the cognitive and modeling processes of visualization of student material, reflection and communication among the subjects of education, in particular, the procedures of progressive foreign language and communicative competence of students in the framework of general interaction with specialists-teachers of foreign languages.

Having analyzed all of the above, we conclude that the digitalization of the educational process should be viewed as the transition to an electronic learning structure with the use of intensification and reorganization of education, based on the creation of an information virtual environment taking into account its characteristics.[4]

The features of the information virtual environment are shown in Figure 1. 


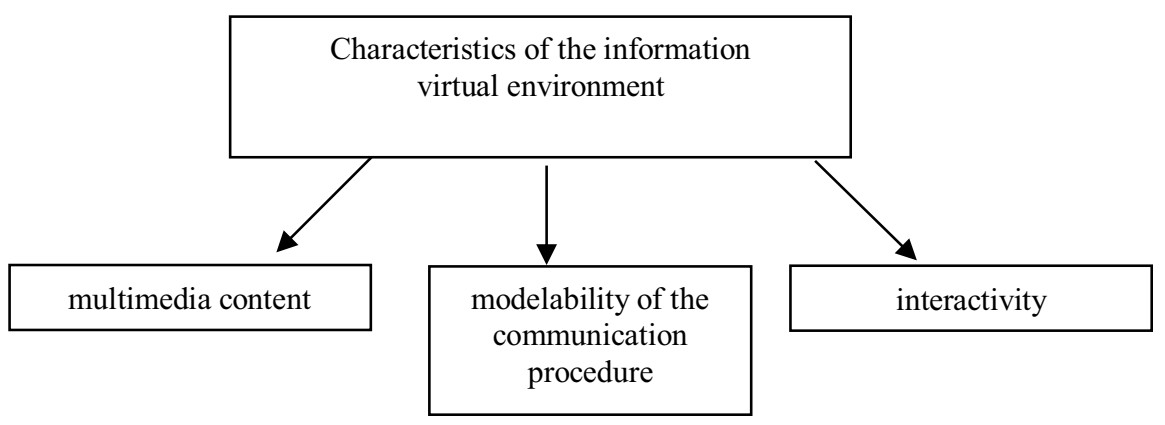

Fig. 1. Characteristics of the virtual information environment.

2. You should also consider the potential of integration of pedagogical, communication and information, the latest digital technologies in the educational process, aimed at creating a base of competencies for University students, but with a different implication in the requirements for the qualification of future professionals in connection with the modification of the current needs of the labour market and nature of educational standards of higher education.

2.1. The first of the characteristics of the digitization procedure of the studying process is that it is absolutely «changes resulting from past methodological basis of education ... It entails the availability of information flow in a variety of forms, not only text, but sound, visualization» [5].

2.2. At the same time, candidates of Pedagogical Sciences T. V. Nikulina and E. B. Starichenko believe that «the universality of the information space will require the search and selection of interesting and relevant content on a constant basis, its significantly high processing speeds. Thus, the digitalization of the educational process leads to its radical and qualitative modification» [6]. Based on such digital transformations in the educational process, a huge number of new terms appear in the literature that characterize the features of learning procedures in such conditions. These include: digital economy, digital educational environment, digital learning, digital technologies, digital media, digital infrastructure, digital pedagogy [7], digital didactics [8], etc.

2.3. Currently, in many universities of the Russian Federation, the digital educational environment is understood as a necessary component of the organizational and pedagogical circumstances of the progress of social and professional competencies of future professionals, and digitalization of the educational process in the training of students of a technical university is not considered an exception. The presence of a digital structure and the use of digital and information and communication technologies is considered an effective way to form the foreign language communicative competence of students of technical universities. Digitalization of the educational process in the field of foreign language teaching includes a wide range of online, digital and electronic abilities for the progress of their foreign language communicative competence based on the use of various components of the digital structure. These include: tools, resources, and technologies. [9]

2.4. The analysis of scientific literature in the field of pedagogy (authors: D. A. Antonova, E. V. Ospennikova, E. V. Spirin, etc.) showed that there are four components in the structure of digital foreign language teaching for students of technical universities:

1) Digital information sources for the purpose of orientation in the Internet space, and in the foreign-language environment of the profession;

2) Information structures for the assistance of administrative and educational work (in particular, communication and foreign language work) within the university;

3) Digital tools for the implementation of the synthesis of communicative and foreign language work of teachers and / or students of a technical university; 
4) Digital educational and methodological materials / complexes as management structures for the procedure of creating foreign-language communicative competence of students of a technical university.

3. Let's analyze the advantages and disadvantages of this system.

3.1. While teaching students a foreign language at a technical university, there is a huge number of digital sources of information that are quite freely available on the Internet. These include: electronic libraries, databases, various websites, online dictionaries of foreign languages (multitran with lexical and thematic sections; Macmillan Dictionary; Cambridge Dictionary; Oxford Learner's Dictionaries under the Oxford University Press), video glossaries and text with a high level of authenticity (regulatory and legal documentation in foreign languages that regulates the foreign economic sphere of different countries).

3.2. As for the the teaching the students of technical universities, most often information structure of the support of the administrative and educational work (in particular communicative foreign language) in these schools is one of the necessary conditions for implementation of the electronic information-educational environment (AIOS) based on the following digital platforms «Moodle» with a large number of digital products (tools, resources and technology), in particular in the field a separate course «Foreign language» (English for specific purposes).

The Moodle platform is very effective for the implementation of electronic office work using the profile of students' communicative and foreign language activities. This system is used to save time in the structural and content modification of various types of digital documents: assessment funds, foreign languages training programs, practical training plans, electronic ponderabilities for recording the degree of formation of foreign language communicative competencies of students, methodological materials, educational and scientific, as well as research works of teachers, students, etc.

Digital tools for various types of educational activities in higher education institutions are most often considered to be a variety of standard tools (Microsoft Word, Microsoft Excel, Microsoft Power Point, etc.), as well as specially developed software tools, such as "Nibelung" for upgrading the classroom with computers into a multimedia interactive environment with increased capabilities of the language lab. These technical means have an interactive and multimedia character, as well as a digital format of foreign language relations between teachers and students. The technological and methodological aspects of this procedure are represented by the following information means: hypertext, mobile media, multimedia, CD-ROM technology, testing programs, computer training programs, telecommunications technologies (these include: teleconferences, television, mail services, etc.), remote types of interaction, such as network/voice / video chats or lectures, teleconferences, etc. In technical universities the structure of the above digital instrumentation is formed through the implementation of various types of digital and communication and information management technologies for the synthesis of the communicative activities of foreign language teachers and students: authorization of teachers of foreign languages Department and students; implementation of e-testing on the subject "foreign language"; the updating of educational and linguistic material, and tasks for personal and project activities of students in the graphic format of such blocks: the network tree, a cluster, pyramid, target, concept map, etc.; electronic evaluation of the impact of foreign language and speech activity of students and the effectiveness of methodical work of teachers of foreign languages Department in digital form, etc. [10]

3.3. In terms of the active individual work on the content of foreign-language educational material, students must be supplied with free access to the content of the EIOS in any location, including all the offices of the Department of Foreign Languages, equipped with computers for each workplace. As part of the support, adjustment and increasing the 
motivation for learning foreign languages, teachers need to apply the EIOS skills for remote testing during online Olympiads in foreign languages, online broadcasts of creative competitions, consultations, as well as practical classes in foreign languages, in particular through programs such as Skype and Zoom.

3.4. In addition, a certain number of information tools, namely simulators to practice in English grammar, only professional sites, social networks, chats, forums, mail are the most effective electronic communication channels, should be fairly freely available on the Internet, thus forming both a collective and individual space within the framework of electronic interaction using computers, as well as mobile devices. Social networks are of great importance for the development of foreign language communicative competence for university students, for example, one of the most popular social network in the Russian Federation "VKontakte", which in turn facilitates the teaching of a foreign language in different communities through the representation of important and interesting facts in a foreign language, vocabulary with transcription and translation, tests for assessing knowledge in grammar, etc. Among the more popular translators, we can mention "Translate.ru" (PROMT) with support for about 19 foreign languages. Google Translate has the ability to translate words, texts, and even web pages completely into 103 foreign languages. The Yandex translator has a distinctive feature-the translation of text from any image. [11]

3.5. The next structural component of digital educational teaching of a foreign language to students of technical universities is digital educational and methodological materials/ complexes for managing the procedure for creating foreign language communicative competencies of university students. This is a special method of creating digital student content in the format of multimedia resources, which are opposed to more financially expensive printed traditional publications, such as: electronic textbooks, presentations in Microsoft Power Point, fragments of professional texts, block diagrams and case studies for point visualization of questions on a specific topic, audio and video materials, tests. [12]

It can be concluded that the competent management of the above-described components of the structure of digital foreign language teaching for students of technical universities will certainly contribute not only to the preservation and modification of a large number of data sets, but also to the verification of the types and methods of foreign language communication both in practical classes and outside the classroom. This approach to the formation of a digital educational environment will give students of technical universities the ability to learn foreign languages according to personal learning curves with the help of individual educational needs, as well as the social and psychological pace of mastering the curriculum in a foreign language.

But despite this, the digitalization of the educational process also entails some contradictions in the aspect of the adequacy of the conditions for creating competencies for students and the set pedagogical goals. An analysis of the resources used by educational institutions indicates that sometimes this variety of new tools turns into a simple technological market [13]. Thus, among the researchers of the issue of digitalization of the current educational process, problems arise that reflect the difficulties that practical teachers have already had to face. Namely: how can the progress and introduction of digital technologies in the field of education affect the quality of basic competencies of university students? Is the absolute rejection of the classical form of education in the direction of digital and e-learning applicable? Is there a model of a mixed type of learning that combines the pedagogical conditions of live communication of the subjects of the educational process with virtual reality technologies, the most effective at the stage of progress of digital pedagogy? 


\section{Discussion}

In addition, in the context of this scientific article, the development of digital competence is not considered the main requirement for specialists in the technical field.

\subsection{And one of the contradictions in the digital educational process is that the choice of digital means by teachers is often not subject to the didactic characteristics of teaching a foreign language in a technical university}

This is the essence of the problem of digitalization of the educational process in the aspect of synthesis of social pedagogics and didactics, as it is impossible to fully convey the organizational and pedagogical features of teaching a foreign language only using electronic devices and digital support structures for foreign students of a technical College. In addition, the social and psychological side of this process involves the acquisition of individual, rather than virtual, experience in the implementation of professional activities, the creation of collaborative skills in a team and awareness of collective needs. The results of recent studies in the field of digital solutions indicated that students of technical universities who study in the traditional form of education "showed the highest results in the field of foreign language acquisition in comparison with students of mixed and computer-based learning groups, both in testing and in creating productive skills" [14]. It is the lack of communication with" live " teachers and fellow students in paired and group types of work that affects the quality of their foreign language communication competence, and long-term distance learning becomes monotonous, undermines health, has a saving effect and forms a negative attitude to digital information. Automation and robotization of production procedures can no longer be stopped, but it is generally premature to talk about the cancellation of teacher services.

\subsection{There are also problems associated with the development of digital educational and methodological materials}

Currently, the quality of multimedia conceptual and cognitive types of object visualization has increased significantly. A digitized textbook is a traditional educational text that is translated into an electronic format, provided with cross-hyperlinks and links to external resources, as well as, possibly, "live pictures" - animation and video fragments." Stimulation of cognitive and creative activity of students in foreign language communication is one of the main functions of the electronic textbook, but in spite of all the positive aspects, they can hardly be considered a "magic wand" that can solve problems of teaching students of non-linguistic disciplines."

\subsection{Although digital technology is indispensable when dealing with a large amount of professional and specialized information, there is also the ambiguous attitude of teachers to digital learning materials and lack of understanding of how they affect the formation of foreign language communicative competence of students of technical higher educational establishments}

There is also the need for language and speech competencies of students as part of their foreign language communicative competencies. Communication processes are aimed at the interaction of students themselves, increasing their interactivity in paired group forms of teaching a foreign language. Therefore, the teacher needs to address various dialogue forms of cooperation: "Student Team Learning", "Learning Together", "Jigsaw", etc. It is 
dialogicality and creativity that are considered as one of the main principles of the most effective formation of foreign-language communicative competencies of students of technical universities in their joint, often non-virtual, foreign-language-communicative activities.

\subsection{The next problematic aspect in the digitalization of education is the preservation of classical methods of working with an electronic textbook within a virtual learning environment in the process of distance learning, which leads to the loss of innovation of this product}

Working with it is only for informational purposes, since the thematic sections of electronic textbooks are disclosed with the help of traditional methodological support. The model of traditional methodological support is shown in Figure 2.

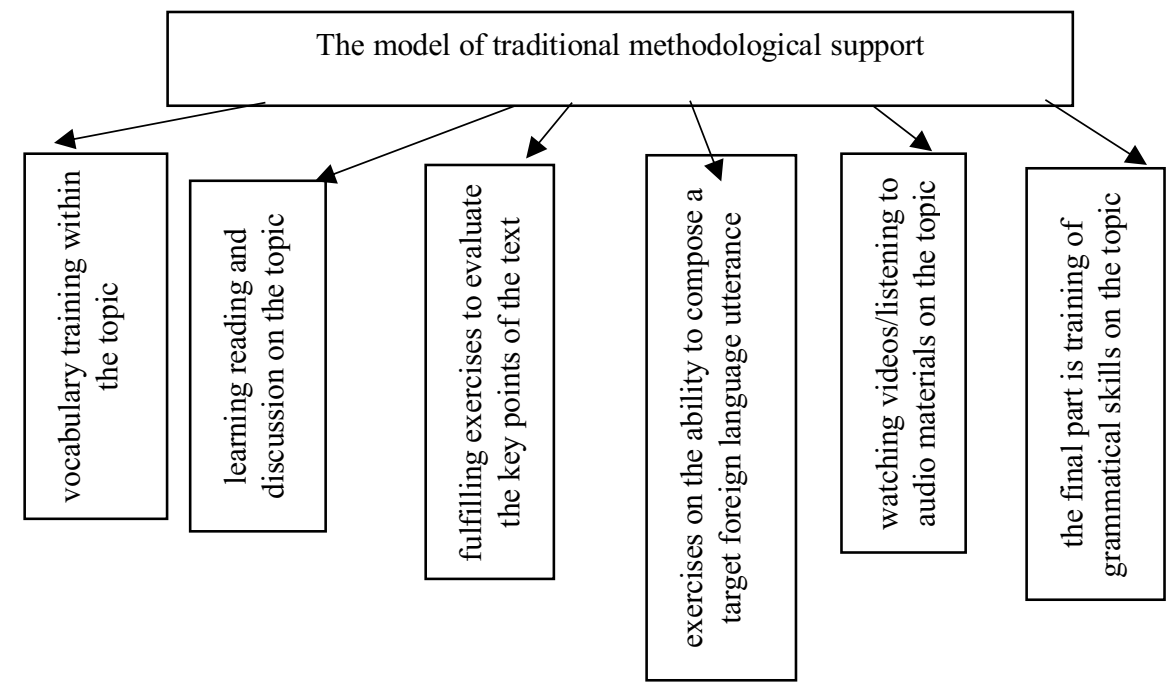

Fig. 2. Model of traditional methodological support.

The teacher should understand that the direct transfer of the traditional format of teaching in the classroom to a virtual environment is impossible without losing the quality of teaching. The essence of solving the above contradiction consists in the fact that the preparation of creative graphics, animation, digital resources can only be regarded as teaching Supplement in the form of digital clarity to the basic communication principles of forming foreign language communicative competence of technical College students.

It should be noted here that an important characteristic of any electronic textbook is that it is created, as a rule, on the basis of limited educational material, but with a large number of animation effects in order to clearly represent conceptually virtual models, for example, natural phenomena, chemical experiments, the principle of operation of mechanical parts, etc. This principle of creating digital resources is practically difficult to implement in the aspect of mastering traditional and modern technical technologies, since their multidimensional knowledge is very complex and requires direct access to video materials on real technical procedures in a specific professional situation. This process becomes even more complicated when the course of cognition becomes foreign-language, which is one of the significant disadvantages of digital foreign language training for specialists. In connection with this fact, the most effective digital tools for the formation of foreign language communication competencies of students are PowerPoint presentations prepared 
by students for subsequent analysis, systematization, generalization and consolidation of the categorical and terminological apparatus of the technical profession, and not an electronic textbook. [15]

\subsection{There is no denying the fact that the ability to quickly modify the educational material in the conditions of rapid updating of cognitive experience in a particular professional field accelerates the process of information exchange, makes it available to other teachers}

Then the question arises about the protection of information and the provision of intellectual property rights in the form of an electronic textbook. For example, creating a new electronic textbook "English in the technical field" is an extremely time-consuming process that requires a lot of time and psychological and pedagogical costs, since the philological education of foreign language teachers does not involve obtaining theoretical and practical experience in the technical field. Teachers have to solve this problem independently, form their own base of technical terms, knowledge about technologies and procedures, and special skills in teaching a foreign language for specialists in this field. Therefore, in any field of activity, as in the field of educational services, there is digital fraud in the form of plagiarism in publishing. Consequently, the process of digitalization of education is accompanied by risks associated with the vulnerability of intellectual property, which leads to large copyright violations, pirated use of information and other people's resources.

\section{Conclusion}

Taking into account the above mentioned facts, it can be stated that the process of digitalization of education has both a positive and a negative impacts on the development of the higher education system in the aspect of teaching foreign languages to future specialists of technical universities. Focusing only on digital teaching of a foreign language to students of a technical university is not able to most qualitatively affect their level of foreign language communication competencies. Since digital information and communication technologies cannot sufficiently ensure the qualitative growth of not only linguistic abilities, professional knowledge, but also socio-cultural qualities of university students, which are socially important for the preservation of moral and ethical norms of behavior in society. It is also worth noting that in the current conditions of the spread of the global coronavirus pandemic COVID-19 and, as a result, the transition to full distance learning, the digitalization of education is most clearly showing its relevance and problematic character.

\section{References}

1. V.G. Khalin, G.V. Chernova, Management consulting, Moscow, RANEPA 10(118), 46 $-63(2018)$

2. E.L. Vartanova, A.V. Vyrkovsky, M.I. Makseenko, S.S. Smirnov, Industry in the Russian media: the digital future: an academic monograph (MediaMir, Moscow, 2017)

3. T.V. Nikulina, E.B. Starichenko, Pedagogical education in Russia, Yekaterinburg, UGPU 8, 107 - 113 (2018) 
4. D.A. Antonova, E.V. Ospennikova, E.V. Spirin, Bulletin of the Perm State Humanitarian and Pedagogical University. Series: information computer technologies in education 14, 5 - 37 (2018)

5. V.I. Blinov, Digital didactics: a fashion trend or a new science? Modern problems of professional and higher education: state and assessment: a collective monograph ("Ekon-Inform", Moscow, 2019)

6. M.T. Gazieva, The use of ICT in teaching and learning the foreign language to prevail the problems in mixed ability groups 51(185), 269-270 (2017) https://moluch.ru/archive/185/46778/

7. A.N. Astanina, EDCRUNCH URAL: New educational Technologies in Higher Education: Global Conference on Technologies in Education (UrFU, Yekaterinburg, 2019)

8. D.V. Bayandin, Higher education in Russia 7, 113-118 (2019)

9. M.A. Morozova, S.A. Klimova, The use of the YouTube video service in foreign language classes 3, 819-821 (2016)

10. B.R. Sami, Distance and virtual learning 2(80), 48-55 (2018)

11. G.K. Nurgalieva, E.V. Artykbaeva, Bulletin of KazNU, series "Pedagogical sciences" 1(35), 9-12 (2019)

12. P.V. Sysoev, Foreign languages at school 2, 2-9 (2017)

13. A.G. Solomatina, Development of students ' speaking and listening skills through educational podcasts 2(14), 130-134 (2017)

14. A.A. Akpanova Bulletin of the L. N. Gumilyov Eurasian National University 3 (2018)

15. D.D. Avetisyan, Teacher of the XXI century 4 (2020) 